\title{
A produção da cidade como negócio: os novos produtos imobiliários no bairro de Campo Grande, Rio de Janeiro
}

The production of the city as a business: the new real estate products in the neighborhood of Campo Grande, Rio de Janeiro

La producción de la ciudad como negocio: los nuevos productos inmobiliarios en el barrio de Campo Grande, Rio de Janeiro

La production de la ville comme entreprise : les nouveaux produits immobiliers dans le quartier de Campo Grande, Rio de Janeiro

\section{Paulo Henrique Araujo Barata}

\section{OpenEdition}

Journals

\section{Edição electrónica}

URL: http://journals.openedition.org/espacoeconomia/15756

DOI: 10.4000/espacoeconomia. 15756

ISSN: 2317-7837

\section{Editora}

Núcleo de Pesquisa Espaço \& Economia

\section{Refêrencia eletrónica}

Paulo Henrique Araujo Barata, « A produção da cidade como negócio: os novos produtos imobiliários no bairro de Campo Grande, Rio de Janeiro », Espaço e Economia [Online], 19 | 2020, posto online no dia 30 agosto 2020, consultado o 10 setembro 2020. URL : http://journals.openedition.org/ espacoeconomia/15756; DOI : https://doi.org/10.4000/espacoeconomia.15756

Este documento foi criado de forma automática no dia 10 setembro 2020.

(c) NUPEE 


\section{A produção da cidade como negócio: os novos produtos imobiliários no bairro de Campo Grande, Rio de Janeiro}

The production of the city as a business: the new real estate products in the neighborhood of Campo Grande, Rio de Janeiro

La producción de la ciudad como negocio: los nuevos productos inmobiliarios en el barrio de Campo Grande, Rio de Janeiro

La production de la ville comme entreprise : les nouveaux produits immobiliers dans le quartier de Campo Grande, Rio de Janeiro

Paulo Henrique Araujo Barata

\section{Introdução}

1 Será essa a última dança do neoliberalismo?

"Reúnam-se, pessoas, onde quer que estejam

E admitam que as águas ao seu redor estão subindo

E aceitem que logo estarão encharcados até os ossos

Se para vocês, seu tempo ainda tem valor

Então é melhor que comecem a nadar

ou afundarão como pedras

Pois os tempos estão mudando"

The times, they are a-changing (Bob Dylan)

2 O artigo foi pensado e elaborado durante a pandemia Covid-19, provocada pelo vírus Sars-Cov-2. Devido às peculiaridades da transmissão, manifestação e tratamento dos infectados pelo vírus, que exigem medidas de fechamento das atividades produtivas e impossibilitam a livre circulação dos trabalhadores pelo espaço, as economias nacionais foram parcialmente paralisadas. O cenário atual aponta para um agudo quadro 
recessivo da economia global. Governos europeus dos países centrais do capitalismo, no coração da União Europeia, parecem inclinados a abandonar as políticas de austeridade implantadas desde a Crise de 2008, que agora parece atingir o seu ápice. As soluções econômicas apresentadas até esse momento apontam o abandono da ortodoxia políticoeconômica ditada pelo neoliberalismo e indicam direcionamento às políticas, hoje vistas como heterodoxas, de um Keynesianismo ainda a ser revisitado e revisto.

3 Nesse primeiro semestre de 2020, não é possível ter certezas sobre os desdobramentos da crise. Porém, é possível perceber que os governos europeus estão discutindo maneiras para escapar da água que está a subir ao seu redor. Parecem ter percebido que precisam nadar ou afundarão como pedras, pois os tempos estão mudando.

4 Entretanto, nas últimas cinco décadas, a economia global seguiu os ditames da política neoliberal, que foi plasmada na dimensão política, social, cultural e materializou-se em formas e objetos no espaço. A interação entre essas dimensões, que estão entrelaçadas e condicionam e são condicionas pela dimensão do espaço, orientou e (re)produziu espaços urbanos pelo sistema-mundo. Fundamentalmente, as cidades são centros terciários fundamentais, locais de trocas e difusão de ideias, interfaces entre as pessoas e as instituições da sociedade. É o lugar do encontro e do lazer, dos serviços básicos à manutenção e desenvolvimento da vida e que oferece o aparato técnico e intelectual para o suporte das atividades econômicas. Diferentes formações socioespaciais materializarão formas singulares, pois as especificidades e a força do lugar absorvem e remodelam as demandas globais ao adaptá-las aos interesses locais, mas essencialmente resultarão em formas com as mesmas funções (BARATA SALGUEIRO, 1996; SANTOS, M., 2009 [1996]).

5 A partir dessas reflexões, podemos nos indagar sobre os desdobramentos do modelo neoliberal na produção do espaço urbano, especialmente de novos produtos imobiliários ligados aos serviços, em um bairro periférico de um país na periferia do sistema capitalista. A interconexão e sincronização das economias nacionais sob o sistema organizado pelo capitalismo na globalização tornou essas economias passíveis de serem submetidas a movimentos e processos semelhantes. Por isso, os mesmos processos ocorrerão dentro do mesmo ciclo em formações socioterritoriais diferentes, mesmo que cronologicamente descompassados por quase uma década. É a condição essencial para a realização da urbanização planetária, como classificada por David Harvey. Assim, torna-se possível entender a implantação do neoliberalismo e os impactos urbanos no Brasil na virada do século XX para o XXI, usando o bairro de Campo Grande como exemplo, e tendo como referência inicial as transformações urbanas em Portugal nas décadas de 1980 e 1990.

6 Em 1986, a combinação da adesão de Portugal à Comunidade Europeia e a estabilidade política, após o término da ditadura de Salazar, garantida por um governo majoritário de centro-esquerda com ideias liberais, são os marcos iniciais da remodelação do Estado Português. O modelo de gestão dos recursos escassos impostos pelo neoliberalismo impunha-se por dois aspectos essenciais: "desenvolvimento de estratégias de racionalização dos serviços públicos e consequente atribuição ao sector privado de funções tradicionalmente dominadas pelo Estado [...]; forte expansão dos serviços de apoio às actividades económicas (incluindo banca e seguros) (FERRÃO e DOMINGUES, 1994, p. 8)". É chamada a atenção para a explosão do crescimento dos serviços de apoio às atividades econômicas, que teria resultado da convergência de uma miríade de fatores externos aliados a outros endógenos. Algumas categorias de serviços foram 
mais impactadas, o que é expresso pela considerável expansão das atividades de consultoria, serviços bancários, os seguros e as operações imobiliárias, com forte caráter especulativo, especialmente, no mercado imobiliário de escritórios.

7 No Brasil, o ano de 1985 é importante para compreender os impulsos iniciais que transformam a cidade como negócio. O fim da política federal de grandes obras públicas, devido à mudança de paradigma do Estado interventor para o Estado neoliberal, força as empreiteiras envolvidas na produção de infraestrutura a migrar para as atividades no mercado imobiliário. A implantação do neoliberalismo ocorrerá no Brasil, a partir do governo Collor, na década de 1990, o primeiro democraticamente eleito após os 21 anos da ditadura civil-militar-empresarial (1964-1985), que foi interrompido devido à crise institucional que o levou ao impeachment. Uma das heranças deixadas por esse governo foi o Tratado de Assunção, fundando o Mercado Comum do Sul (Mercosul). O projeto neoliberal é retomado, a partir de 1995, com o governo liderado pelo então presidente Fernando Henrique Cardoso, do Partido da Social Democracia Brasileira (PSDB), histórica e majoritariamente de centro-esquerda e influenciado pelos novos rumos da chamada "Terceira Via" do Partido Trabalhista inglês. Em dezembro de 1994, às vésperas do início desse governo, é assinado o Tratado de Ouro Preto, conferindo uma estrutura institucional básica e conferiu ao Mercosul personalidade jurídica de direito internacional (MERCOSUL, s/d).

O governo brasileiro guardava consideráveis semelhanças com o governo português de 1986. Ambos foram guiados pela expansão do neoliberalismo herdado do período liberal-conservador liderado por Reagan / Thatcher. À época do estabelecimento do PSDB no comando da economia brasileira, o contexto econômico nacional estava em estabilização saindo da situação periclitante dos anos 1980 (MARANGONI, 2012; BRASIL, 1996). No Brasil, a década anterior é considerada a "década perdida", pela ocorrência dos altos índices de inflação, baixas taxas de crescimento do PIB que agravaram o quadro de desigualdade social e a falência literal das cidades, vide o caso da cidade do Rio de Janeiro. Qual seria o novo papel das cidades nesse cenário decadente? E qual seria a ação do Estado como um dos agentes produtores do espaço?

\section{O neoliberalismo: o guia ideológico da produção do espaço urbano}

9 O período compreendido entre as décadas de 1970 e 2020, o período da pósmodernidade ou a chamada sociedade pós-industrial, é marcado pelo discurso neoliberal. O Estado é apropriado por forças que o despontecializa, dando vez aos agentes privados, às corporações e às organizações supranacionais que comandariam todo o processo de (re)construção do espaço mundial (HAESBAERT, 2006; SANTOS, M., 2009 [1996]). O Estado surgiria como mediador do conflito entre os interesses de cada indivíduo e aqueles da comunidade. Por isso, seria um ser independente e com caráter conciliatório. No entanto, a própria sociedade cria um instrumento com arcabouço jurídico, tributário e coercitivo bem consolidados, e que acaba sendo usufruído pela classe social dirigente: os detentores do capital.

10 As ações da classe dirigente não acontecem livremente, pois, antes de qualquer ação, existem marcos jurídicos pautando a sua atuação. De fato, as ações a serem engendradas pelos controladores do capital precisam ser de alguma forma 
(des)reguladas para que alcancem maior efetividade dentro do plano desses atores. 0 Estado e seus órgãos assumem esse papel de (des)regulamentador ao operarem combinados como um braço executivo da burguesia (HARVEY, 2006). O Estado é apropriado por grupos políticos para autorizar, gerenciar e executar projetos econômicos de uma parcela específica da sociedade. Souza (2010), aliás, faz restrições a tal pensamento leninista que, segundo o autor, resume o Estado como braço executivo da classe dominante e desconsidera a dialética dos conflitos e contradições do capitalismo. Todavia, o mesmo autor concorda que na estrutura geral das relações "a lógica da ação do Estado, numa sociedade capitalista, tenda a ser a reprodução da ordem vigente" (SOUZA, 2010, p. 29), mas que não é necessariamente verdade em pontos específicos ou no "varejo", como diz. O mercado orientará as políticas urbanas, ainda que dependa da legitimidade do poder do Estado para concretizar suas ações.

11 Santos (2015) é inequívoco ao afirmar o novo papel do espaço urbano no neoliberalismo. A escala urbano-metropolitana era vista como algo essencial no universo de acumulação desse novo momento da acumulação capitalista. A compreensão do papel da cidade deveria ser alterada, pois, do lugar do negócio, do espaço de trocas, essa torna-se a própria mercadoria a ser trocada: a cidade tornou-se o próprio grande negócio, na forma de seus objetos intencionalmente produzidos para tal fim.

A emergência de um "novo regime econômico", impulsionado pelo destacado papel das finanças e dos serviços assumido no fim do século XX, redimensiona a importância dos grandes centros metropolitanos na dinâmica de acumulação que desenrola cada vez mais na escala global. A emergência dessa nova configuração econômica, [...] atribui maior importância aos segmentos financeiros e de serviços [...] (SANTOS, C., 2015, p.18).

12 As forças que foram estabelecidas no espaço urbano se opõem ou se alinham na luta pela primazia da produção do espaço segundo interesses momentâneos e pontuais, e esse conflito pode ser sempre mantido, atenuado ou suprimido, mas sempre necessitará de regulação. Entretanto, na contramão da tendência mundial, ou atestando que o Estado sempre se constituiu como ator fundamental na produção do espaço, no bairro de Campo Grande, o Estado impõe suas estratégias ao regular a produção do espaço que se entrelaça a reprodução do capital investido pelos agentes privados na forma de novos produtos imobiliários. Assim, “o Estado capitalista desempenha múltiplos papéis em relação à produção do espaço. Essa multiplicidade decorre do fato do Estado constituir uma arena na qual diferentes interesses e conflitos se enfrentam" (CORRÊA, 2011, p. 45). O Estado seria o controlador tanto econômico quanto político de toda a sociedade, tutelando-a de acordo com seus instrumentos jurídicos estabelecidos (CARLOS, 2011). Assim, o Estado continua a ter um papel essencial no processo de (re)construção da cidade.

\section{Antecedentes da produção do espaço terciário em Campo Grande, Rio de Janeiro}

13 Na segunda metade da década de 1960, as ruas centrais do bairro de Campo Grande registravam um comércio expressivo. Àquela época, Campo Grande já se estabelecia como centro comercial, tornando o bairro um dos subcentros da cidade do Rio de 
Janeiro em apoio a expansão urbana sobre as áreas rurais (SOARES, 1990 [1968]) ${ }^{1}$. O bairro remetia a

uma pequena cidade, com seu importante centro comercial próximo à estação, ruas bem calçadas e limpas, bairros residenciais bem diferenciados socialmente, linhas de bonde e lotação ligando o núcleo à zona rural ou aos novos loteamentos. (...) Um comércio numeroso e diversificado atende à população suburbana e à população da zona rural de Campo Grande e Guaratiba (...) (SOARES, 1965, p. 376).

14 A formação de Campo Grande como subcentro não decorre apenas do alinhamento de forças endógenas, sejam esses locais ou nacionais, apenas. Existem forças exógenas que atuam mesmo que indiretamente na organização e produção do espaço nessa localidade. A articulação ocorre devido ao inexorável atrelamento dos espaços ao sistema criado pelo alinhamento da ordem econômica, social, política e moral em determinado período histórico. No mesmo período e nos mais distintos pontos do espaço vemos surgir formas espaciais semelhantes e desenvolvidas para atender demandas decorrentes do sistema vigente (SANTOS, M., 2008 [1979]).

15 A formação de um bairro periférico, em um país periférico, corresponde ao reordenamento das forças emitidas a partir dos países centrais em dado momento histórico, cujas repercussões são sentidas nos planos sociais, econômicos, políticos e espaciais. Apesar de ser um bairro periférico, Campo Grande estava sincronizado com os processos mais gerais da produção do espaço pelo globo. A partir dos anos 1970, nos EUA, e nas décadas seguintes do final do século XX, a cidade cresceu difusa e multipolar devido à implantação de espaços de lazer e centros comerciais nas suas periferias (CAPEL, 2002).

16 As necessidades do capital, alinhadas à evolução das técnicas, são fatores que causam a modificação, substituição e desaparecimento de determinados elementos (re)estruturando (novos) espaços. Nesse cenário complexo da produção capitalista do espaço urbano, compreender a criação e recuperação de uma forma espacial abre portas para entender as motivações da intervenção em determinado tempo e suas possibilidades futuras.

17 No bairro de Campo Grande, no lugar dos centros comerciais, a rua comercial ${ }^{2}$ foi a forma possível de ser realizada nas ruas centrais do bairro. 0 projeto que criou o "Calçadão" na rua Coronel Agostinho, tornando-o núcleo do comércio campograndense, coincide temporalmente com a difusão urbana, policentralidade e criação de centros comerciais nos EUA, por exemplo.

18 O projeto do "Calçadão" foi fruto da aliança das forças locais organizadas pela Associação Comercial e Industrial de Campo Grande (ACICG-RJ), cuja liderança estava a cargo do então administrador regional do bairro, Moacir Barros Bastos, alinhadas com a Prefeitura da Cidade do Rio de Janeiro, que à época estava sob o comando do Prefeito Marcos Tamoyo. A radical transformação do logradouro, transformado de residencial para comercial, foi inaugurada no dia 08/11/1976, com a presença do prefeito (TAMOYO..., 1976, p. 12). A intenção da intervenção urbana pela conjunção de forças público-privada era explícita e divulgada pelos meios midiáticos: o objetivo era a transformação de Campo Grande em um centro de serviços (CAMPO GRANDE..., 1976, p. 10). Uma das consequências dessa intervenção foi a modificação considerável na oferta de serviços e comércio. $\mathrm{O}$ setor terciário foi sofisticado pelo estabelecimento de serviços bancários e financeiros, e as atividades comerciais foram incrementadas, como verificado por Menezes (1999). 
19 Os rumos e desdobramentos periclitantes do plano político-econômico nacional nos anos 1980 deixaram marcas de decadência por todo o espaço urbano da cidade do Rio de Janeiro. A virada das décadas de 1980 para 1990 é marcada pela ocupação dos logradouros pelo comércio de rua, atividade que materializa o circuito inferior da economia (SANTOS, M., 2008 [1979]) no espaço urbano. O espaço comercial da cidade sofria um lento e gradual processo de degradação sem a reação satisfatória dos poderes estabelecidos para a sua recuperação. Com o álibi da ordenação do espaço urbano, a esfera municipal anunciou reformas urbanísticas para o disciplinamento das atividades que ocupavam as ruas do Centro e principais subcentros da cidade (COMBATE..., 1990, p. 4).

\section{A Urbanização Planetária: a produção da cidade como negócio}

20 O processo de produção do espaço age de maneira diversa pelo tecido urbano. As estratégias de produção abrangem um leque considerável de possibilidades que residem na reabilitação de antigas áreas, no reaproveitamento de áreas subutilizadas, na renovação pontual ou em mancha de espaços obsoletos, na ocupação de áreas livres por novas construções e na implantação de infraestrutura adequada de acesso aos espaços (BARATA SALGUEIRO, 1994). Dentre todas as possibilidades aventadas, a reabilitação visa

manter a população local, aumentando [...] a qualidade do espaço urbano, promovendo a dinamização de algumas actividades económicas, contribuindo portanto para a melhoria da qualidade de vida dos residentes e, indirectamente, para uma melhor imagem e funcionamento da cidade (BARATA SALGUEIRO, 1994, p. 82).

21 As modificações da política urbana estão diretamente relacionadas ao plano econômico mundial. Se anteriormente o fordismo ditava os rumos do desenvolvimento urbano, a partir desse momento o neoliberalismo seria o carro-chefe da política urbana, tendo um papel hegemônico nos modelos de cidade e de planejamento urbano hoje vigentes. Essa modalidade de regime de acumulação se diferencia do anterior por ter cunho predominantemente financeiro - cuja principal característica é a apropriação de riqueza por estratégias com bases em de atividades especulativas no mercado imobiliário e financeiro e nas transações comerciais (VAINER, 2000; BIENENSTEIN, 2009). Ao adotar o viés neoliberal, o Estado aplica o receituário do empreendedorismo urbano (HARVEY, 2006), torna-se um facilitador da transformação da cidade em negócio. A missão do Estado torna-se atrair fluxos de produção, financeiros e de consumo de alta mobilidade e flexibilidade para seu recorte espacial, e em parceria com os agentes privados do capital alinhavar os interesses do lugar com os poderes públicos locais (HARVEY, 2006; OLIVEIRA, 2008). Buscou-se a criação das condições necessárias às empresas para que se estabeleçam em determinados espaços, ou seja, a criação de um ambiente favorável aos negócios pela implantação de chamarizes capazes de atrair capital.

Na década de 1990, o discurso vigente era de mercantilização da cidade, tornando o espaço urbano mais uma mercadoria a ser negociada pelo capital. Como qualquer mercadoria o espaço deveria ser revitalizado e repotencializado para que as suas vocações pudessem ser exploradas pelo mercado. Se a cidade é um produto, uma 
mercadoria, é necessário traçar estratégicas de promoção e marketing capazes de instalá-lo no imaginário e vendê-la. Para tanto é necessário formar um conjunto de ideias relacionado a tal produto que resultem numa imagem a ser comercializada.

As prefeituras alinhadas ao capital privado imobiliário eram os principais agentes interessados nos projetos urbanísticos, pois era a forma possível para colocar em marcha as desejadas requalificações urbanas. Essas foram as pontas de lança no processo de (re)produção e (re)valorização do espaço urbano.

A perspectiva de crescimento acelerado, de ampliação do fluxo de investimentos para a cidade, contexto de uma economia mundializada altamente competitiva, criava uma espécie de consenso que estava na base da soldagem de um pacto político tácito entre o Estado, o capital e a sociedade civil locais [...]. As estratégias de acumulação do capital não avançam sem o dispositivo prático e efetivo da produção e reprodução do espaço urbano (SANTOS, C., 2015, p. 33).

24 Atingir esse objetivo demandaria drásticas intervenções no espaço urbano. A reforma dos centros comerciais dos principais subcentros da cidade do Rio de Janeiro, aconteceu via um projeto de transformação urbana de viés flexível que revitalizou e repontecializou as vocações de tais espaços da cidade.

25 O Projeto Rio Cidade foi o mote do governo do prefeito da Cidade do Rio de Janeiro, César Maia, nos anos 1990. Foi o instrumento público utilizado para materializar o ideário da acumulação flexível na produção dos espaços urbanos. Apesar de ser apresentado com uma forte carga simbólica relacionada à recuperação da imagem da cidade, a elevação da autoestima do carioca e a valorização do sentimento de pertencimento, na prática, os seus objetivos revelaram-se mais pragmáticos focados na "revitalização da rua, a revalorização dos bairros, a reconstrução de espaços públicos, a recuperação de centros comerciais, a reconstituição de corredores de bairros, a requalificação da imagem da cidade, o reequilíbrio psicossocial (OLIVEIRA, 2008)". A intenção do projeto era a (re)valorização e (re)afirmação dos bairros que àquela época eram centralidades comerciais importantes na estrutura citadina (BARATA, 2012).

26 No projeto Rio Cidade, a revalorização do bairro teve a rua como seu elemento principal. A rua, por ser o corredor que estrutura a imagem da cidade e, assim, um dos seus elementos estruturantes, é o ponto de partida para a revalorização do bairro (OLIVEIRA, 2008). As ruas centrais do bairro de Campo Grande já concentravam os estabelecimentos do comércio e serviços do local. Logo, o Rio Cidade revalorizou, revitalizou e requalificou a centralidade existente no bairro. Tais objetivos do projeto são confirmados ao identificarmos que os bairros sob esse processo de (re)produção estavam em deterioração e foram efetivamente recuperados. Uma das ações primordiais era resgatá-los como polos de atração, como centralidades, na sua área de influência. A recuperação ocorreu tanto no plano do mercado imobiliário residencial quanto no comercial, sendo um meio para desafogar o congestionado Centro, bairro da cidade do Rio de Janeiro (PULICI, 2005). Segundo David Harvey,

A urbanização como um meio de acumulação de capital era relativamente limitada nos tempos de Marx, não estava na linha de frente do que estava acontecendo. Ao passo que cada vez mais o capital tem dificuldade em encontrar coisas para produzir. Então, o que ele faz cada vez mais é encontrar novos mercados, novas configurações e, de certa forma, o que ele fez foi transformar a urbanização em um grande conjunto de práticas de mercado. Por meio do qual os lucros podem ser realizados e o capital poderia ser acumulado. [...] Na verdade, para o capital, essa tem sido uma característica menor na sua história. Porém, eu gostaria de apresentar que, ao longo dos últimos 30 ou 40 anos, 
ele tem se tornado uma parte predominante de sua história. [...] Na verdade, uma das respostas ao desejo para acumulação perpétua de capital tem sido a construção do que poderíamos chamar de urbanização planetária. Isso quer dizer que há um processo de urbanização que agora é global e que tem qualidades semelhantes (ANTIPODEONLINE, 2020).

Barata Salgueiro (1994) identifica o boom imobiliário de Lisboa nos anos 1980 concentrado em dois produtos: a habitação de luxo e os escritórios. No recorte do bairro de Campo Grande, não podemos afirmar que o segmento de luxo foi a mola propulsora do mercado imobiliário ${ }^{3}$. Entretanto, a partir da segunda metade da década de 1990 até a implosão da economia nacional a partir do quarto mandato presidencial do Partido dos Trabalhadores (PT), na década de 2010, a análise do mercado imobiliário realizada por Barata (2012) revela que o bairro sofreu um processo visível e quantificável de explosão na oferta de unidades de habitação e de salas em prédios de escritórios e centros comerciais. "Esta reestruturação financeira e da produção do espaço construído materializada no boom da oferta de escritórios são corolário necessário ao avanço da transnacionalização da economia no sentido da globalização (BARATA SALGUEIRO, 1994, p. 81)".

28 No artigo em questão, Barata Salgueiro aborda a construção de infraestrutura adequada, materializada nos prédios de escritórios, para os serviços especializados e de apoio voltados para as empresas transnacionais em solo português. A característica da demanda é um ponto divergente do caso do bairro de Campo Grande cuja demanda é da comunidade local. Os pontos que unem a produção do espaço ao atual momento da Globalização, e sustentam nossa argumentação, são a terciarização das cidades e a venda dos objetos, destinados ao setor terciário, como produtos imobiliários.

29 Usando o caso da Região Metropolitana de São Paulo como indicativo dessa tendência no Brasil, é verificado que no intervalo compreendido de 1995 a 2000, mesma época das reformas urbanas no Rio de Janeiro, 20,8\% dos investimentos realizados no recorte foram concentrados em atividades imobiliárias. É um indício de uma nova tendência do setor de investimentos da economia e, por consequência, é ligada "à expansão e à concentração do setor de serviços na metrópole um poderoso ressurgimento dos capitais investidos no imobiliário acompanhado de uma indústria da construção civil voltada para a construção de escritórios verticais" (SANTOS, C., 2015, p. 35).

30 O Estado age publicando nova legislação que permita a realização das ações guiadas por essa nova tendência do mercado. O Projeto de Estruturação Urbana (PEU) de Campo Grande, estabelecido pela Lei Complementar Municipal no 72, de 27 de julho de 2004, estabelece as limitações do novo zoneamento e das regras para a produção nesses espaços. Como pode ser visto na planta do projeto, a legislação destina duas zonas voltadas para o comércio e serviços, as Zonas de Comércio e Serviços (ZCS) 1 e 2, permitindo que na ZCS 2 sejam construídos objetos com até 8 pavimentos, permitindo a maior produtividade do espaço construído e, assim, a maior lucratividade auferida sobre o produto imobiliário. 
Imagem 1: Zoneamento estabelecido pelo PEU Campo Grande 2004.

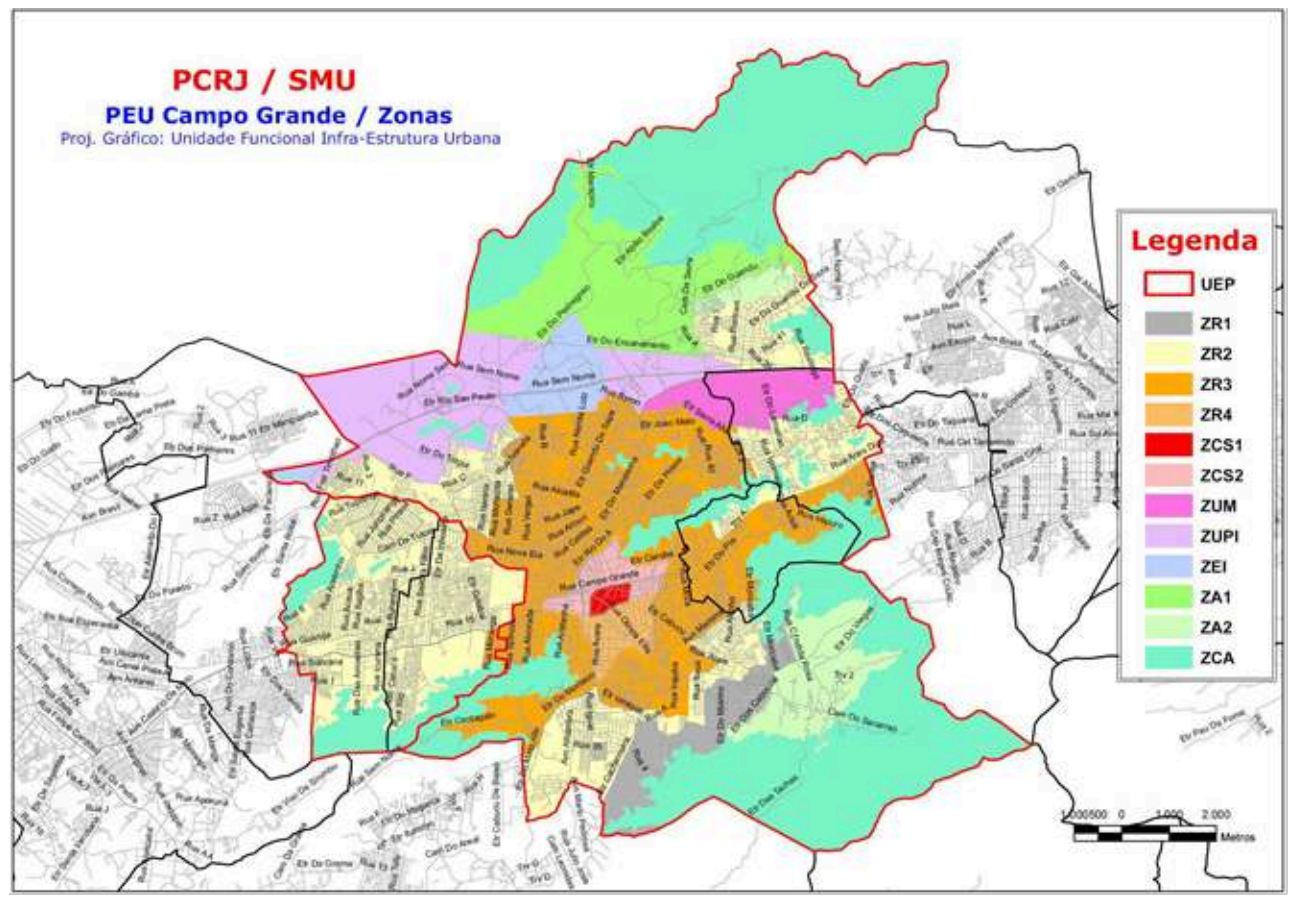

Fonte: Lei Complementar nº 72 de 27/07/20044

31 A continuidade da transformação da cidade e região do Rio de Janeiro em negócio é incentivada pelo Plano Diretor 2011 da Cidade do Rio de Janeiro. O sítio eletrônico da Secretaria Municipal de Urbanismo, da Prefeitura da Cidade do Rio de Janeiro, apresenta o plano nos seguintes termos

O Plano Diretor é um instrumento legal que propõe uma política de desenvolvimento urbano e orienta o processo de planejamento do Município. Esta política tem por objetivo ordenar o desenvolvimento da cidade, garantir seu pleno funcionamento e o bem-estar de seus habitantes. [...] O Plano Diretor pretende orientar as ações dos agentes públicos e privados, determinando as prioridades para aplicação dos recursos orçamentários e investimentos (RIO DE JANEIRO [Município], 2011).

O zoneamento estabelecido pela legislação enquadra o centro do bairro de Campo Grande na Macrozona de Ocupação Assistida. Nessa macrozona, a ocupação urbana é orientada pelos vetores de crescimento previstos na Seção II "Dos vetores de crescimento da cidade", artigo 33 que nos seus incisos III, IV e V orienta a ocupação de vazios urbanos no leito da estrada de ferro, na Zona Oeste, a intensificação da ocupação junto aos centros de comércio e de serviços e indica a associação de investimentos da iniciativa privada aos recursos das três esferas do poder público na implantação de infraestrutura e equipamentos urbanos, respectivamente. $O$ zoneamento estabelecido pelo Plano Diretor pode ser visualizado na imagem a seguir: 
Imagem 2: Macrozoneamento do Plano Diretor da Cidade do Rio de Janeiro 2011

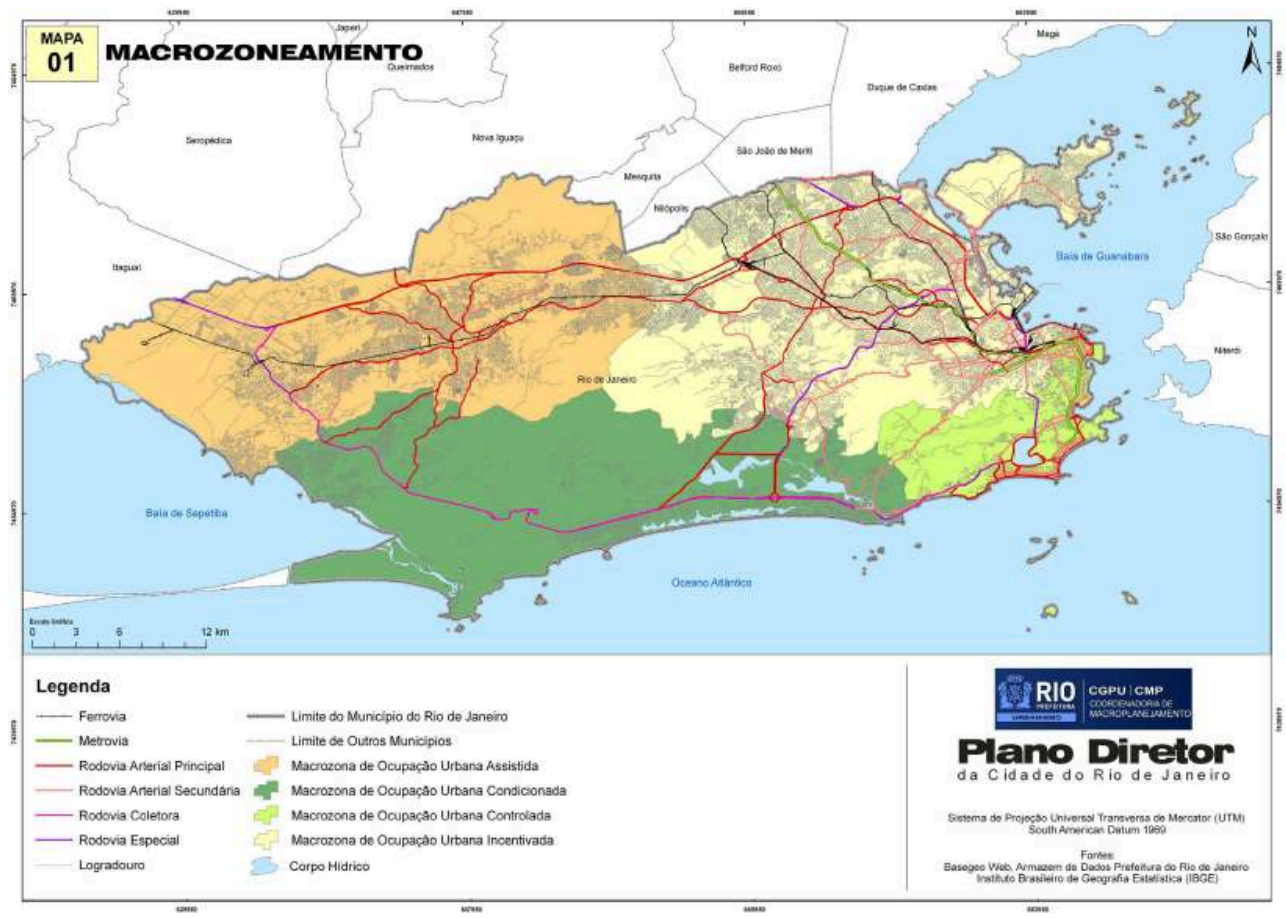

FONTE: LEI COMPLEMENTAR N ${ }^{\circ}$ 111/2011, PREFEITURA DA CIDADE DO RIO DE JANEIRO. DISPONÍVEL EM: HTTP://WWW.RIO.RJ.gOV.BR/DLSTATIC/10112/139339/DLFE-242117.PDF/

MAPAIMACROZONEAMENTO.PDF. ACESSADO EM: 15 AgO. 2020.

O parágrafo primeiro do artigo quinto nos concede uma informação preciosa acerca das intenções de reorganização do setor terciário no espaço da cidade do Rio de Janeiro.

A organização espacial dos centros de comércio e serviços deverá contribuir para a redução da concentração das atividades econômicas na zona sul e na Barra da Tijuca e para o fortalecimento das concentrações de comércio e serviços da Tijuca, Madureira, Taquara e Campo Grande (RIO DE JANEIRO [Município], 2011).

34 A legislação é clara ao indicar a relação capital público-privado em consonância na (re)produção e (re)organização do espaço terciário da cidade. Indica, inclusive, a localização dos investimentos voltados para o comércio e serviços, justamente na área central de alguns bairros, no intuito de reorganizar o setor terciário pelo tecido socioespacial da cidade do Rio de Janeiro, adensando intencionalmente o terciário do bairro de Campo Grande, além de outros subcentros tradicionais da cidade. No recorte em tela, a produção de novos produtos imobiliários na forma de prédios de serviços é essencial para a concretização do plano previsto para o desenvolvimento da cidade. $O$ quadro a seguir mostra a produção de prédios para escritórios no século XXI.

Quadro 1: Produtos imobiliários destinados ao terciário em Campo Grande produzidos de 2000 a 2019

\begin{tabular}{|c|c|c|c|c|}
\hline Nome & Tipo & $\begin{array}{l}\text { Empreendedor } \\
\text { Imobiliário }\end{array}$ & Localização & $\begin{array}{l}\text { Ano de } \\
\text { lançamento }\end{array}$ \\
\hline $\begin{array}{l}\text { West Medical } \\
\text { Center }\end{array}$ & $\begin{array}{ll}\text { Prédio de } \\
\text { Serviços }\end{array}$ & R2 Radical & $\begin{array}{l}\text { Zona de Comércio e } \\
\text { Serviços } 2\end{array}$ & 2008 \\
\hline
\end{tabular}




\begin{tabular}{|c|c|c|c|c|}
\hline $\begin{array}{l}\text { Conjunto Mont } \\
\text { Blanc }\end{array}$ & $\begin{array}{l}\text { Prédio de uso } \\
\text { misto }\end{array}$ & AGM Imóveis & $\begin{array}{l}\text { Zona de Comércio e } \\
\text { Serviços } 2\end{array}$ & 2008 \\
\hline West Offices & $\begin{array}{l}\text { Prédio de } \\
\text { Serviços }\end{array}$ & ECIA - Irmãos Araujo & Zona Residencial 3 & 2011 \\
\hline $\begin{array}{l}\text { Campo Grande } \\
\text { Office \& Mall }\end{array}$ & $\begin{array}{l}\text { Prédio de } \\
\text { Serviços }\end{array}$ & Even & Zona Residencial 4 & 2013 \\
\hline Business Completo & $\begin{array}{l}\text { Prédio de } \\
\text { Serviços }\end{array}$ & Rossi & $\begin{array}{l}\text { Zona de Comércio e } \\
\text { Serviços } 1\end{array}$ & 2012 \\
\hline West Tower & $\mid \begin{array}{ll}\text { Prédio } & \text { de } \\
\text { Serviços } & \end{array}$ & MDL & Zona Residencial 4 & 2010 \\
\hline Plaza Offices & $\begin{array}{l}\text { Prédio de } \\
\text { Serviços }\end{array}$ & PDG Realty & $\begin{array}{l}\text { Zona de Comércio e } \\
\text { Serviços } 2\end{array}$ & 2008 \\
\hline $\begin{array}{l}\text { Pátio } \quad \text { Campo } \\
\text { Grande }\end{array}$ & $\begin{array}{l}\text { Prédio de } \\
\text { Serviços }\end{array}$ & Queiroz Galvão & $\begin{array}{l}\text { Zona de Comércio e } \\
\text { Serviços } 2\end{array}$ & 2013 \\
\hline Passeio Empresarial & $\begin{array}{l}\text { Prédio de } \\
\text { Serviços }\end{array}$ & Santa Isabel & $\begin{array}{l}\text { Zona de Comércio e } \\
\text { Serviços } 2\end{array}$ & 2015 \\
\hline
\end{tabular}

Fonte: Barata, 2020.

A peça de propaganda no sítio eletrônico da construtora Queiroz Galvão elenca as qualidades da localização do seu produto. Tendo em mente a estrutura como categoria de análise do espaço, identificamos que a empreendedora imobiliária aponta que uma das qualidades do empreendimento Pátio Campo Grande reside na sua proximidade ao "Calçadão". A rua comercial constituiu-se como objeto que exerce forte polarização na atração diária de considerável fluxo de consumidores, e, pela proximidade, tal prédio poderia ser beneficiado na absorção de parte desse fluxo.

Um projeto moderno e arrojado, no point de Campo Grande, ao lado do "Calçadão", onde circulam milhares de pessoas. Um empreendimento comercial com conceito inovador na região, que une a conveniência das lojas no térreo à praticidade das salas comerciais nos demais pavimentos. Perfeito para o seu negócio e uma excelente opção de investimento (QUEIROZ GALVÃO, s/d) 5 .

É interessante perceber, e isso abre o caminho para nova pesquisa, que mesmo os edifícios que concentram serviços especializados como, por exemplo, consultórios médicos e odontológicos, escritórios de advocacia e contabilidade e outros ${ }^{6}$, em seu andar térreo são ocupados por atividades comerciais. A técnica arquitetônica empregada na construção dos novos empreendimentos molda novos elementos na paisagem urbana. A arquitetura pós-moderna dos objetos comerciais é revelada na imagem a seguir pelas fachadas envidraçadas desses objetos que contrastam com as fachadas predominantemente de concreto dos edifícios e casario mais antigos no entorno. 
Imagem 3: Novos produtos imobiliários destinados ao setor terciário. No sentido horário: A) Business Completo, B) Montblanc Towers, C) Pátio Campo Grande, D) West Medical Center.
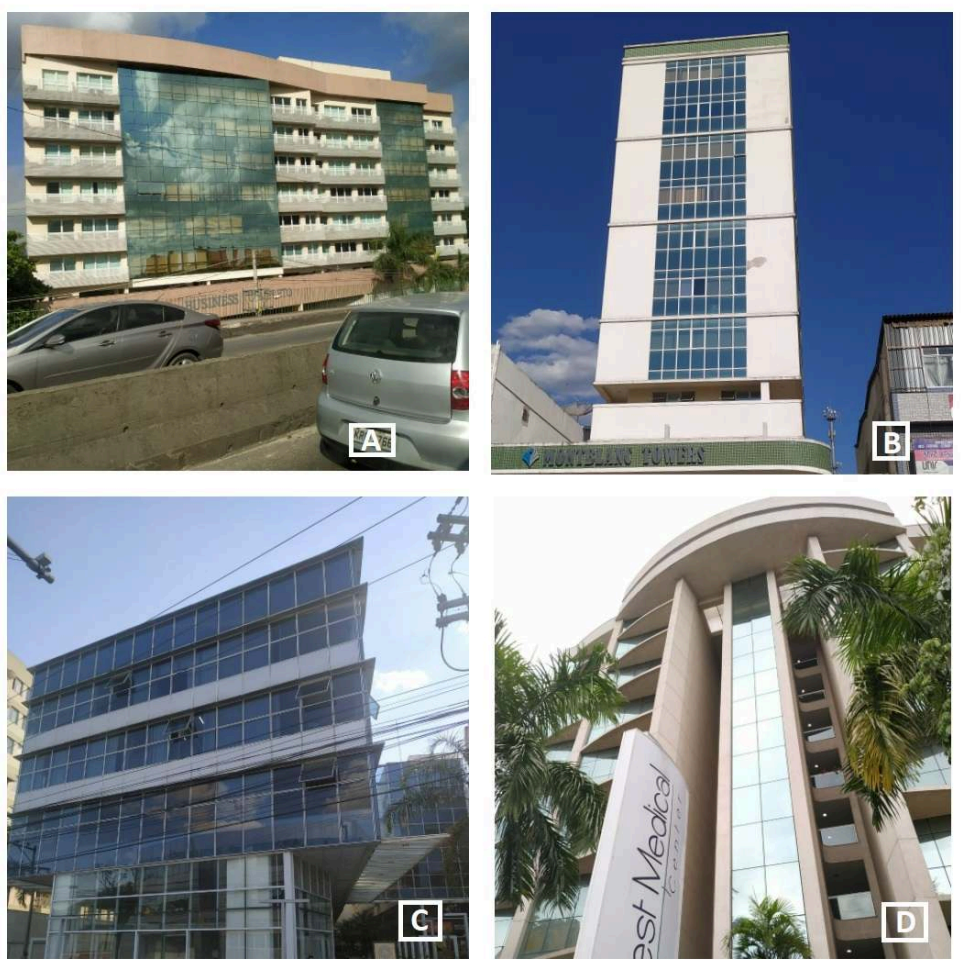

Fonte: Barata, 2020.

O maior número de produtos imobiliários concentra-se no eixo rodoviário formado pelas Estradas do Mendanha e do Monteiro ${ }^{7}$, especialmente na ZCS 2. São quatro prédios de escritórios - West Offices, Plaza Offices, Business Completo e West Tower, um prédio especializado em consultórios médicos - West Medical Center e dois centros comerciais planejados - o West Shopping e o Park Shopping Campo Grande ${ }^{8}$. 0 eixo dá acesso direto a Avenida Brasil pela estrada do Mendanha e é um dos possíveis caminhos para Barra da Tijuca via estrada do Monteiro. Por ser área contígua à ZCS 1, o espaço comercial tradicional do bairro, a ZCS2 tornou-se uma alternativa ao congestionado centro tradicional do bairro de Campo Grande que sofre gargalos devido à falta de terrenos disponíveis e uso voltado para o comércio varejista, atraindo fluxos provenientes de até outras cidades, como Nova Iguaçu. Os antigos prédios comerciais, como o Campo Grande Trade Center, na rua Coronel Agostinho, estão ou na capacidade máxima de ocupação, ou não possuem estrutura adequada para as exigências comerciais atuais, como salas de reuniões, palestras e afins. O padrão dos prédios nesse eixo permite uma maior sofisticação das atividades e serviços que podem ser ofertados ao público. Acima de tudo, configura-se como uma nova área que poderá ser explorada oferecendo serviços e comércio raros ou inexistentes no antigo espaço comercial, e constituindo-se como estoque imobiliário a ser explorado pelo rentismo local.

Os produtos imobiliários são produzidos por incorporadores de diferentes escalas de tamanho e atuação. Como exemplo, temos dois incorporadores, o primeiro de atuação na escala local e o segundo de atuação nacional. Tradicionalmente, o incorporador que mais se destacou na área foi o Grupo Ecia-Irmãos Araujo, com sede no bairro de Jacarepaguá, Rio de Janeiro. A empresa de capital limitado fundada em 1955, com 
atividades voltadas para engenharia, entra no mercado imobiliário como proprietária fundiária, construtora e incorporadora ${ }^{9}$. A área de atuação sempre foi tipicamente periférica, nos limites da Zona Oeste do Rio de Janeiro. Em sítio contíguo ao seu empreendimento comercial (West Shopping) e próximo aos seus inúmeros loteamentos nas Estradas do Mendanha e Posse, a incorporadora produziu o West Offices, um prédio comercial para escritórios e consultórios médicos.

41 A partir dos anos 2000, empresas consideradas grandes, de capital aberto e abrangência de atuação nacional, como a PDG, adentraram o mercado imobiliário comercial do bairro. Sobre a escala de atuação da PDG destaca-se a sua presença em 17 estados e o Distrito Federal e mais de 100 cidades brasileiras ${ }^{10}$. A capacidade de investimentos da empresa é materializada no maior objeto produzido voltado aos serviços no bairro. $O$ produto imobiliário realizado pela empresa no bairro é vendido com as seguintes palavras

Conheça agora um dos polos comerciais mais importantes da cidade. Próximo do Hospital Rocha Faria, a estação de trem, com farta opção de transporte e muito mais. Salas comerciais numa super infraestrutura para implantação de escritórios, consultórios e muito mais, tudo com uma arquitetura importante, num terreno de aproximadamente $3.060 \mathrm{~m}^{2}$ (PLAZA OFFICE, $\left.\mathrm{s} / \mathrm{d}\right)^{11}$.

Além das suas próprias qualidades materializadas na infraestrutura produzida para o empreendimento, o prédio de serviços Plaza offices é vendido pela incorporadora com ênfase nas qualidades resultantes da estrutura espacial na qual se insere: a sua localização no centro comercial de Campo Grande e, como consequência, as vantagens dos outros objetos de serviços aos quais está relacionado por ser parte de tal estrutura. É a (re)produção de formas espaciais relacionadas ao terciário que continuamente consolida e renova o bairro como centralidade terciária na cidade do Rio de Janeiro. A imagem a seguir revela o objeto em si.

Imagem 4: Produto imobiliário da PDG Realty - Plaza Office em Campo Grande, Rio de Janeiro.

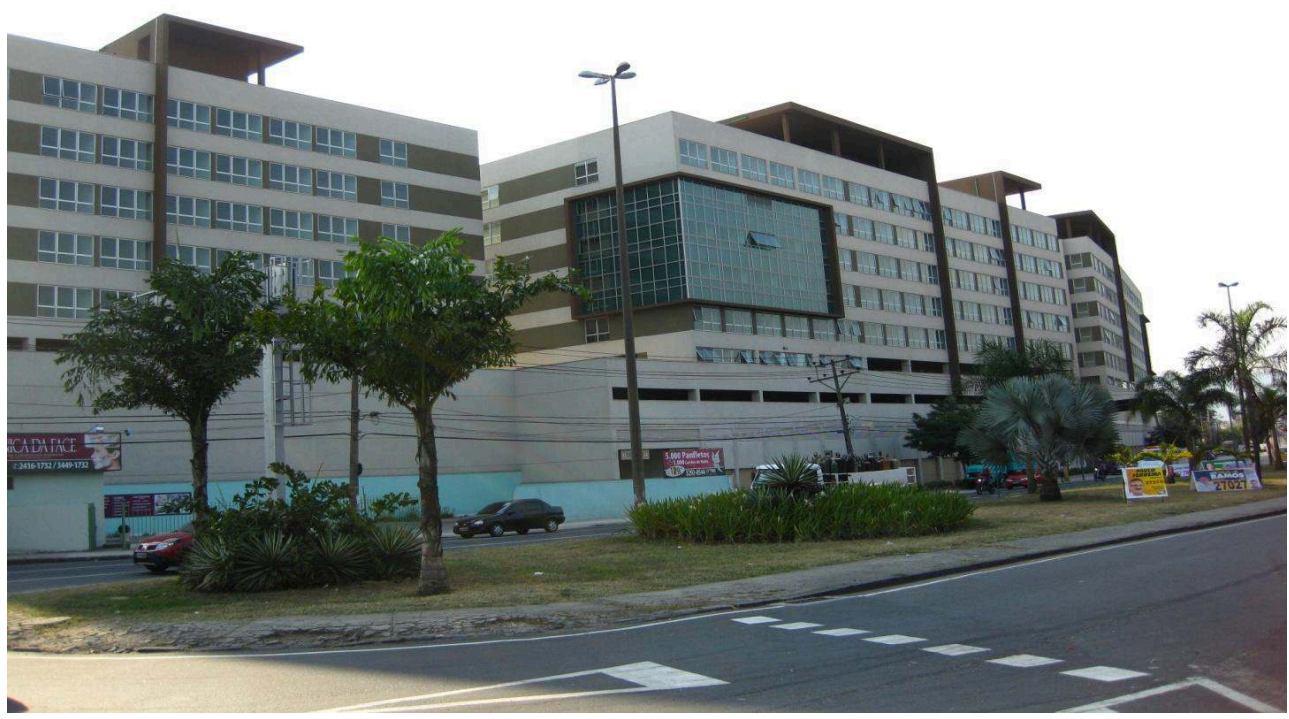

Fonte: BARATA, 2012.

Como podemos visualizar na imagem anterior, a monumentalidade do empreendimento é uma marca da nova paisagem urbana do bairro. Essa paisagem 
torna-se a cada dia mais moldada pelos objetos destinados ao setor terciário para atender ao capital na produção da cidade como negócio.

\section{Considerações Finais}

44 No recorte temporal estabelecido, a virada dos séculos XX e XXI, é possível perceber como as mudanças da economia mundial reverberariam na escala urbana pelos projetos de reestruturação urbana alinhados com o setor terciário.

45 Refletindo a partir de Santos (2009), asseveramos que as sucessivas etapas de produção do espaço do bairro são espelhadas pela requalificação do espaço terciário, resultando na renovação da estrutura espacial devido à produção de objetos espaciais modernos. Há intenções e finalidades específicas conferidas aos objetos ao serem produzidos em determinados pontos do tecido espacial urbano. A ordem espacial é constantemente (re)arranjada e (re)modernizada para atender aos interesses dos atores hegemônicos, que programam e produzem a produção do espaço urbano de Campo Grande.

A exploração do setor terciário como vocação local do bairro foi um meio para superação do modelo industrial desenvolvimentista, que falhou para atingir o desenvolvimento do bairro na década de $1970^{12}$, e que agora renova a oferta de objetos comerciais, na forma de prédios de escritórios e insere o bairro nos novos rumos da economia contemporânea das grandes cidades, na virada dos séculos XX para o XXI.

\section{BIBLIOGRAFIA}

ANTIPODEONLINE. David Harvey and the City - An Antipode Foundation film. 2020. (12m36s). Disponível em: https://www.youtube.com/watch?v=iPGvXhicF2M. Acesso em: 12 jun. 2020.

BARATA, Paulo Henrique Araujo. O Estado capitalista e a produção desigual do espaço no bairro de Campo Grande - Rio de Janeiro. 2012. Dissertação (Mestrado em Geografia). Instituto de Geografia da Universidade do Estado do Rio de Janeiro, Rio de Janeiro, 2012.

BARATA, Paulo Henrique Araujo. O Sertão vira Calçadão: A transformação do rural em urbano em Campo Grande, Rio de Janeiro, ao longo do século XX. 2019. Tese (Doutorado em Geografia) Instituto de Geografia da Universidade do Estado do Rio de Janeiro, Rio de Janeiro, 2020.

BARATA SALGUEIRO, Teresa. Do Comércio à Distribuição: roteiros de uma mudança. Oeiras: Celta, 1996.

BARATA SALGUEIRO, Teresa. Novos produtos imobiliários e reestruturação urbana. Finisterra, XXIX, 57, 1994, pp. 79-101.

BIENENSTEIN, Glauco. Convergência e Consenso: política e economia da urbanização da periferia do capitalismo. In: 12 ENCONTRO DE GEÓGRAFOS DE AMÉRICA LATINA, 2009, Montevidéu. Anais do 12 Encontro de Geógrafos de América Latina, 12 EGAL, 2009. v. 1 
BRASIL. Balanço dos 24 meses do Plano Real. Ministério da Fazenda: Brasília, 1996. Disponível em: http://fazenda.gov.br/acesso-a-informacao/acoes-e-programas/plano-real/ balanco_dos_24_meses_do_real.pdf. Acessado em: 10 fev. 2019.

CABRAL, Claudia Piantá Costa. Tipologias comerciais em Porto Alegre: da rua comercial ao shopping center. 1996. Dissertação (Mestrado em Arquitetura). Faculdade de Arquitetura, Universidade Federal do Rio Grande do Sul, Rio Grande do Sul, 1996.

CAMPO GRANDE pretende ser um centro de serviços. O Globo, Rio de Janeiro, 12 ago. 1976, p. 12.

CAPEL, Horacio. La Morfologia de las Ciudades. Editorial: Ediciones del Serbal, 2002.

CARLOS, Ana Fani Alessandri. Da Organização à Produção do Espaço no Movimento do Pensamento Geográfico. In: CARLOS, Ana Fani Alessandri; SOUZA, Marcelo Lopes de; e SPOSITO, Maria Encarnação Beltrão (org.). A Produção do Espaço Urbano: agentes e processos, escalas e desafios. São Paulo: Contexto, 2011.

CARRERAS, Carles. Os novos espaços de consumo em Barcelona. Finisterra, XXIX, 57, p.103-117, 1994.

COMBATE aos camelôs. Jornal do Brasil. Rio de Janeiro, 7 abr. 1990. Caderno Cidade, p. 4. CORRÊA, Roberto Lobato. Sobre Agentes Sociais, Escala e Produção do Espaço: Um Texto Para Discussão. In: CARLOS, Ana Fani Alessandri; SOUZA, Marcelo Lopes de; e SPOSITO, Maria Encarnação Beltrão (org.). A Produção do Espaço Urbano: agentes e processos, escalas e desafios. São Paulo: Contexto, 2011.

FERRÃO, João; e DOMINGUES, Álvaro. Portugal: as condições territoriais de um processo de terciarização vulnerável. Finisterra, XXIX, 57, 1994, pp. 5-42.

HARVEY, David. A Produção Capitalista do Espaço. São Paulo: Annablume, 2006.

LEFEBVRE, Henri. O direito à cidade. São Paulo: Centauro, 2008 [1968].

LYNCH, Kevin. A imagem da cidade. São Paulo: Martins Fontes, 1980 [1960].

MARANGONI, Gilberto. Desafios do Desenvolvimento. Anos 1980, década perdida ou ganha? 2012. Ano 9. Edição 72 - 15/06/2012. Disponível em: https://www.ipea.gov.br/desafios/index.php? option=com_content\&id=2759:catid=28\&Itemid=23. Acessado em: 12 ago. 2020.

MENEZES, Dilson de Alvarenga. Na Assembleia Constituinte. Volume I. Rio de Janeiro: Dilson de Alvarenga Menezes, 1999.

MERCOSUL. Saiba mais sobre o Mercosul. Disponível em: http://www.mercosul.gov.br/saibamais-sobre-o-mercosul. Acesso em: 19 ago. 2020.

OLIVEIRA, Márcio Piñon de. Projeto Rio Cidade: intervenção urbanística, planejamento urbano e restrição à cidadania na cidade do Rio de Janeiro. Diez años de cambios en el Mundo, en la Geografía y en las Ciencias Sociales, 1999-2008. Scripta Nova. Revista Electrónica de Geografía y Ciencias Sociales. Barcelona: Universidad de Barcelona, vol. XII, no270, ago. 2008. Disponível em: http://www.ub.edu/geocrit/sn/sn-270/sn-270-117.htm. Acessado em: 19 ago. 2020.

PDG. Sobre a PDG. Disponível em: https://www.pdg.com.br/sobre-pdg. Acessado em: 19 ago. 2020.

PINTAUDI, Silvana Maria. A cidade e as formas de comércio. In: CARLOS, Ana Fani Alessandri et. al. (org.). Novos caminhos da Geografia. São Paulo: Contexto, 2002. 
PINTAUDI, Silvana Maria. Anotações Sobre o Espaço do Comércio e do Consumo In: CARRERAS, C; PACHECO, S. M. M. (Org.). Cidade e comércio: a rua comercial na perspectiva internacional. Rio de Janeiro: Armazém das Letras, 2009.

PLAZA OFFICE. Passeio Virtual, s/d. Disponível em: https://empresarialplazaoffice.com.br/. Acessado em: 19 ago. 2020.

PULICI, Andréa Paulo da Cunha. Intervenção pública na década de 90: uma análise dos impactos espaciais do Programa Rio - Cidade no mercado imobiliário da cidade do Rio de Janeiro. 2005. 155 f. Dissertação (Mestrado em Planejamento Urbano e Regional). Instituto de Pesquisa e Planejamento Urbano e Regional, Universidade Federal do Rio de Janeiro, 2005.

QUEIROZ GALVÃO. Pátio Campo Grande. Disponível em: https://www.qgdi.com.br/v2/rj/imovel/ patio-campo-grande. Acessado em: 19 ago. 2020.

RIO DE JANEIRO (Município). Lei Complementar n.ำ 111, de 1ํ de fevereiro de 2011. Dispõe sobre a Política Urbana e Ambiental do Município, institui o Plano Diretor de Desenvolvimento Urbano Sustentável do Município do Rio de Janeiro e dá outras providências. Rio de Janeiro: Prefeitura da Cidade do Rio de Janeiro, 2011. Disponível em https://mail.camara.rj.gov.br/APL/Legislativos/ contlei.nsf/573ad0b372ea8c96032564ffo0629eae/cdd6a33fa14df524832578300076df48? OpenDocument. Acesso em 19 ago. 2020.

RIO DE JANEIRO (Município). Lei Complementar nº 72, de 27 de julho de 2004. Institui o PEU Campo Grande - Projeto de Estruturação Urbana dos Bairros de Campo Grande, Santíssimo, Senador Vasconcelos, Cosmos e Inhoaíba, integrantes das Unidades Espaciais de Planejamento 51 e 52 (UEP 51 e 52), e dá outras providências. Disponível em http://www.rio.rj.gov.br/web/smu/ exibeconteudo?id=2800025. Acesso em: 19 ago. 2020.

RIO DE JANEIRO (Município). Saturnino Braga. Rio de Janeiro: Arquivo Geral da Cidade do Rio de Janeiro, s/d. Disponível em: http://www.rio.gov.br/web/arquivogeral/ccnlep/saturnino-braga. Acessado em: 19 ago. 2020.

SANTOS, Carlos Eduardo Sobrinho dos. O subúrbio de um lugar (in)comum e sua centralidade: o caso de Campo Grande. 2014. Monografia (Especialização em Educação Ambiental). Fundação Educacional Unificada Campograndense, 2014.

SANTOS, César Simoni. Do lugar do negócio à cidade como negócio. In: CARLOS, Ana Fani A.; VOLOCHKO, Danilo; ALVAREZ, Isabel Aparecida Pinto. A cidade como negócio. São Paulo: Contexto, 2015.

SANTOS, Milton. A Natureza do Espaço: Técnica e Tempo, Razão e Emoção. São Paulo: EDUSP, 2009 [1996].

SANTOS, Milton. 0 espaço dividido: os dois circuitos da economia urbana. $2^{\underline{a}}$ ed. São Paulo: EDUSP, 2008 [1979].

SOARES, Maria Therezinha de Segadas. Bairros, bairros suburbanos e subcentros (1968). In: BERNARDES, Lysia M.C.; SOARES, Maria T. de S. Rio de Janeiro: cidade e região. Rio de Janeiro: Secretaria Municipal de Cultura: Dep. Geral de Doc. e Inf. Cultural, 1990.

SOARES, Maria Therezinha de Segadas. Fisionomia e Estrutura do Rio de Janeiro. Revista Brasileira de Geografia. Ano XXVII, n 3, Julho-Setembro de 1965.

SOUZA, Marcelo Lopes. Mudar a Cidade: uma introdução crítica ao planejamento e à gestão urbanos. Rio de Janeiro: Bertrand Brasil, 2010.

TAMOYO quer dar auto-suficiência ao município. O Globo, Rio de Janeiro, 9 nov. 1976, p. 12. 
VAINER, Carlos B. Pátria, empresa e mercadoria: Notas sobre a estratégia discursiva do Planejamento Estratégico Urbano. In: VAINER, Carlos. B.; MARICATO, Ermínia.; ARANTES, Otília. A cidade do pensamento único, desmanchando consensos, Petrópolis: Vozes, 2000.

\section{NOTAS}

1. O artigo foi originalmente publicado no ano de 1968. Transcrito de Associação dos Geógrafos Brasileiros (Secção Regional do Rio de Janeiro). Curso de Geografia da Guanabara. Rio de Janeiro, Instituto Brasileiro de Geografia, 1968.

2. As formas comerciais passam por distintos momentos acerca de sua definição. Atendo-nos a um dos diversos momentos de apreensão acerca da rua comercial, uma possível definição seria "[...] uma rua delimitada total ou parcialmente por uma sucessão de lojas que coincidem com o alinhamento, cada uma delas acessível diretamente da calçada, estando ou não localizada sob edificações destinadas a outros fins quaisquer. Por definição a rua comercial inclui o espaço público: as lojas necessariamente limitam com este, quer seja resolvido como espaço unicamente pedestre, quer como espaço destinado a pedestres e veículos" (CABRAL, 1996, p. 45).

3. PULICI (2005) estuda os impactos do Projeto Rio Cidade e identifica a valorização do espaço dos bairros que receberam o referido projeto. BARATA (2012) revela, através da análise dos relatórios mensais da Associação de Dirigentes de Empresas do Mercado Imobiliário (ADEMI-RJ), a posição emergente do bairro de Campo Grande no mercado imobiliário voltado para produtos imobiliários residenciais nas primeiras décadas do século XXI.

4. Disponível em < http://www.rio.rj.gov.br/dlstatic/10112/138931/DLFE-3256.pdf/ ZONEAMENTO_CG.pdf $>$. Acessado em: 14/03/2012.

5. Disponível em: https://www.qgdi.com.br/v2/rj/imovel/patio-campo-grande. Acesso em: 20/03/2020.

6. A identificação dos tipos de serviços mais comuns foi feita por trabalhos de campo no ano de 2019.

7. Sobre os eixos rodoviários guiarem a produção imobiliária consultar BARATA, Paulo Henrique Araujo. A Expansão do Mercado Imobiliário na cidade do Rio de Janeiro: A Dinâmica Socioespacial Campograndense. 69 f. Monografia (Especialização em Políticas Territoriais no Estado do Rio de Janeiro) - Instituto de Geografia, Universidade do Estado do Rio de Janeiro, 2009 e CASSEMIRO, Rafael Fernandes. O papel do capital incorporador e do Estado na produção de moradias e na reestruturação urbana do bairro de Campo Grande. 141 f. Dissertação (Mestrado em Geografia) -Instituto de Geografia, Universidade do Estado do Rio de Janeiro, 2011.

8. O bairro de Campo Grande pode ser entendido por suas múltiplas centralidades que são possibilitadas pelas diversas apreensões do espaço geográfico. Em outras palavras, as centralidades estão ligadas aos aspectos culturais, históricos e econômicos. Nos atendo a dimensão econômica, convém conjecturar a expansão do centro do bairro, tendo como seus novos limites o West Shopping, na Estrada do Mendanha, e o Park Shopping, na Estrada do Monteiro, tendo a rua Coronel Agostinho o seu núcleo central. Sobre as centralidades do bairro de Campo Grande consultar SANTOS, Carlos Eduardo Sobrinho dos. O subúrbio de um lugar (in)comum e sua centralidade: o caso de Campo 
Grande. 2014. Monografia (Especialização em Educação Ambiental). Fundação Educacional Unificada Campograndense.

9. Disponível em <http://www.ecia.com.br/historico.php>. Acessado em: 12/03/2020.

10. Disponível em <https://www.pdg.com.br/sobre-pdg>. Acessado em: 12/03/2020.

11. Disponível em: <https://empresarialplazaoffice.com.br/>. Acessado em: 12/03/2020.

12. A falha do projeto de industrialização para a promoção do desenvolvimento pleno do bairro pode ser lida em BARATA, Paulo Henrique Araujo. O Sertão vira Calçadão: A transformação do rural em urbano em Campo Grande, Rio de Janeiro, ao longo do século XX. 2019. Tese (Doutorado em Geografia) - Instituto de Geografia da Universidade do Estado do Rio de Janeiro, Rio de Janeiro.

\section{RESUMOS}

O artigo tem como objetivo desvelar o entrelaçamento da terciarização da economia urbana com a fase neoliberal do capitalismo no bairro de Campo Grande. Visa explicar a produção do espaço urbano, como mercadoria em si engendrado por políticas públicas, sob a orientação de interesses privados, e a consequente expansão da oferta de objetos comerciais na forma de produtos imobiliários para o setor terciário no bairro de Campo Grande, no recorte temporal de 1990 a 2019, dentro do contexto macroeconômico neoliberal. Baseamos a análise em Teresa Barata Salgueiro para abordar a (re)produção do espaço refletida na forma de produtos imobiliários na forma de prédios de serviços. O papel do Estado, como um dos agentes produtores do espaço na atual fase neoliberal do capitalismo, é subsidiado pelo pensamento de David Harvey e Milton Santos. Observamos e identificamos a expressiva expansão da produção e oferta de prédios de escritórios voltados ao setor terciário a partir dos anos 2000.

The article aims to unveil the intertwining of the urban economy with the neoliberal moment of capitalism in the Campo Grande neighborhood. It aims to explain the production of urban space, as a commodity engendered by public policies, under the guidance of private interests, and the consequent expansion of the supply of commercial objects in the form of real estate products for the tertiary sector in the Campo Grande neighborhood, in the clipping from 1990 to 2019, within the neoliberal macroeconomic context. We based the analysis on Teresa Barata Salgueiro to address the (re) production of space reflected in the form of real estate products in the form of service buildings. The role of the State, as one of the space-producing agents, in the current neoliberal phase of capitalism is subsidized by the thinking of David Harvey and Milton Santos. We observed and identified the significant expansion of production and supply of office buildings aimed at the tertiary sector since the 2000s.

El artículo tiene como objetivo revelar el entrelazamiento del sector terciario de la economía urbana con la fase neoliberal del capitalismo en el barrio de Campo Grande. Pretende explicar la producción del espacio urbano, como una mercancía engendrado por las políticas públicas, bajo la orientación de intereses privados, y la consecuente expansión de la oferta de objetos comerciales en forma de productos inmobiliarios para el sector terciario en el barrio de Campo Grande, en el recorte. de 1990 a 2019, en el contexto macroeconómico neoliberal. Basamos el análisis en Teresa Barata Salgueiro para abordar la (re) producción de espacio reflejada en forma 
de productos inmobiliarios en forma de edificios de servicios. El papel del Estado, como uno de los agentes productores de espacio, en la actual fase neoliberal del capitalismo está subvencionado por el pensamiento de David Harvey y Milton Santos. Observamos e identificamos la expansión expresiva de la producción y oferta de edificios de oficinas destinados al sector terciario desde la década de 2000.

L'article vise à révéler l'imbrication de la tertiarisation de l'économie urbaine avec la phase néolibérale du capitalisme dans le quartier de Campo Grande. Il vise à expliquer la production de l'espace urbain, en tant que marchandise engendrée par les politiques publiques, sous la direction d'intérêts privés, et l'expansion conséquente de l'offre d'objets commerciaux sous forme de produits immobiliers pour le secteur tertiaire dans le quartier Campo Grande, dans le période de 1990 à 2019, dans le contexte macroéconomique néolibéral. Nous avons basé notre analyse sur Teresa Barata Salgueiro pour aborder la (re)production de l'espace reflétée sous la forme de produits immobiliers sous la forme de bâtiments de service. Le rôle de l'État, en tant que l'un des agents producteurs de l'espace dans la phase néolibérale actuelle du capitalisme, est subventionné par la réflexion de David Harvey et Milton Santos. Nous avons observé et identifié l'expansion significative de la production et de l'offre d'immeubles de bureaux destinés au secteur tertiaire depuis les années 2000.

\section{ÍNDICE}

Mots-clés: secteur tertiaire ; bâtiments de service ; production immobilière.

Palavras-chave: setor terciário, prédios de serviços, produção imobiliária.

Palabras claves: sector terciario, edificios de servicios, producción inmobiliaria.

Keywords: tertiary sector, service buildings, real estate production

\section{AUTOR}

\section{PAULO HENRIQUE ARAUJO BARATA}

Doutor em Geografia pelo Programa de Pós-Graduação em Geografia da Universidade do Estado do Rio de Janeiro (PPGEO - UERJ). Professor I de Geografia na Secretaria de Educação do Estado do Rio de Janeiro (Seeduc-RJ). E-mail: phabarata@gmail.com. 